\title{
GIDALARDA BULUNAN KÜFLERİN TANIMLANMASINDA KULLANILAN YÖNTEMLER
}

\author{
İlkim Emenli, Gülten Tiryaki Gündüz* \\ Ege Üniversitesi, Mühendislik Fakültesi, Gıda Mühendisliği Bölümü, İzmir, Türkiye
}

Geliş / Received: 18.02.2019; Kabul / Accepted: 13.07.2019; Online bask1 / Published online: 25.07.2019

Emenli, İ., Gündüz, G.T. (2019). Gıdalarda bulunan küflerin tanımlanmasında kullanılan yöntemler. GIDA (2019) 44 (4): 692-706 doi: 10.15237/gida.GD19044

Emenli, I., Gundur, G.T. (2019). Methods for identification of molds in foods. GIDA (2019) 44 (4): 692-706 doi: 10.15237/gida.GD19044

\section{ÖZ}

Küfler doğada hava, toprak, su ve organik maddeler üzerinde yaygin olarak bulunabilen mikroorganizmalardır. Küfler tarafindan üretilen toksik metabolitler nedeniyle, küflerin insan ve hayvan sağlığı üzerinde olumsuz etkileri bulunmaktadır. Küfler gıdaların bozulmasına neden olarak ekonomik kayıplara da sebep olmaktadır. Gıdalarda gelişen küflerin tanımlanması dirençli türler, mikotoksijenik türler ve küf gelişiminin inhibisyonu gibi konularda çalışmalar yapılmasında gereklidir. Küflerin tanımlanması koloni morfolojisi ve mikroskobik özelliklerinin belirlenmesine dayanan geleneksel yöntemler ile gerçekleştirilmektedir. Geleneksel yöntemlerin zaman alıcı olması ve deneyimli personel gerektirmesi nedeniyle, daha hızlı ve güvenilir yöntemlere ihtiyaç duyulmaktadır. Hızlı yöntemlerin maliyeti yüksek olup, aynı zamanda veri tabanlarının yetersiz olması nedeniyle kapsamlı araştırmalar ile standartlaştırılması gerekmektedir. Geleneksel ve hızlı yöntemlerin birlikte kullanılması çalışmaların doğruluğunu arttırmaktadır. Bu derleme çalışmasında, küflerin tanımlanmasında kullanılan geleneksel yöntemler, moleküler yöntemler, matriks ile desteklenmiş lazer desorpsiyon/iyonizasyon uçuş zamanı kütle spektrometresi (MALDI-TOF MS) ve fourier transform infrared spektroskopisi (FT-IR) yöntemleri incelenmiştir.

Anahtar kelimeler: Küf, tanımlama yöntemleri, MALDI-TOF, FT-IR, moleküler tanımlama

\section{METHODS FOR IDENTIFICATION OF MOLDS IN FOODS}

\begin{abstract}
Molds are ubiquitous microorganisms in nature found on air, soil, water and organic matter. Molds can adversely affect the health of humans and animals by producing toxic metabolites. Molds also cause spoilage of foods which results in economic loss. Identification of molds grown in foods is crucial for the studies on inhibition of mold growth on foods, knowledge of resistant and mycotoxigenic species. Conventional identification procedures are based on the recognition of the colony morphology and microscobic observations. Since traditional identification procedures are time consuming and require specified personnel, there is a need for more rapid and reliable techniques to identify molds. Rapid methods are expensive and need to be standardized with extensive studies due to insufficient databases. Combination of conventional and rapid methods increases the accuracy of the studies. In this review, conventional, molecular, matrix-assisted laser desorption/ionisation time-of-flight (MALDI-TOF) and fourier transform infrared spectroscopy (FT-IR) methods used to identify molds were investigated.
\end{abstract}

Keywords: Molds, identification methods, MALDI-TOF, FT-IR, molecular identification

* Yazışmalardan sorumlu yazar/Corresponding author:

$\square$ gtgunduz@gmail.com ; gulten.tiryaki.gunduz@ege.edu.tr $\oslash(+90) 2323113003$ 县 (+90) 2323114831 


\section{GİRİ̧̧}

Küfler, glukan ve kitin içeren hücre duvarına sahip, ökaryotik, doğada yaygın olarak bulunan önemli bir mikroorganizma grubu olup; tarım, tıp, g1da, ilaç ve kozmetik endüstrileri gibi birçok alanda çeşitli sorunlara yol açmaktadır (Lecellier vd., 2014; Lima ve Santos, 2017). Özellikle karbonhidrat, protein, yağ ve nem açısından zengin olan gıdalar, küfler için yaşam alanı oluşturmaktadır. Küfler, mikrobiyel aktivite sonucunda gidaların bozulmasına, gıda atıklarının oluşmasina yol açtı̆̆ı ve ekonomik kayıplara sebep olduğu için gıda endüstrisi ve tüketiciler için önemli bir sorundur (Garnier vd., 2017).

Küfler, tarım ve gıda endüstrisinde hammaddelerin ve işlenmiş gıdaların bozulmasindan sorumludur ve mikotoksin üretebilmelerinden dolayı ciddi sağllk riskleri oluşturabilmektedir (Lecellier vd., 2014). Mikotoksin, küfler tarafından üretilen toksik özellikteki ikincil bileşiklerdir (Heperkan, 2014). İngiltere'de 1960 yllında 100000 hindinin ölümüne sebep olan "Turkey X disease" olarak adlandırilan salgin sonrasinda, toksik metabolitlerin üretebilmesinden dolay1 küflerin insan ve hayvan sağlığ için tehlike oluşturduğu bilincine varllmıştır (Heperkan, 2014; Jiang vd., 2016). Küfler tarafindan üretilen mikotoksinler, gıdanın küflü kısımlardan diğer kısımlarına difüze olabilmektedir. Küfler, bozulma etkeni ve kalite kaybına sebep olmasinın yanı sıra kontrollü koşullarda kullanıldıklarında; organik asit, protein, antibiyotik ve pigment gibi ikincil metabolitleri üretme yeteneklerinden dolayı tıp ve gida endüstrilerindeki uygulamalarda kullanılmaktadır (Wakai vd., 2017). Küflerin tanımlanması ile yararlı özelliklerinin keşfedilmesi de mümkün olabilmektedir.

Gıda bozulmaları ile ilişkili başlıca fungal gruplar, zerofilik, 1sıya dayanıklı, koruyucu maddelere dayanıklı, anaerobik ve psikrofilik küflerdir (RicoMunoz vd., 2018). Gıda güvenliği açısından en önemli küfler Aspergillus, Penicillium, Fusarium ve Alternaria spp.'dir (Bhunia, 2018).

Gıdalarda küf gelişiminin inhibisyonu, dirençli türlerin belirlenmesi, mikotoksin üreten ve bozulmaya neden olan türlerin tanımlanması ve küflerin özelliklerinin araştırılması önemlidir (Houbraken ve Samson, 2017). Küflerin geleneksel olarak tanımlanmas1, koloni morfolojisi ve mikroskobik özelliklerinin belirlenmesine dayanmaktadır. Bu nedenle küflerin tanımlanması zaman alıcıdır ve deneyimli laboratuvarlarda bile hatalı sonuçlara ulaşılabilmektedir (Angeletti, 2017). Son yıllarda, küflerin tanımlanması için kültür bazlı olmayan yöntemlerin kullanılması yönünde çalışmalar hız kazanmıştır. Moleküler yöntemler, küflerin tür seviyesine kadar tanımlanması için uygun standartlara sahiptir. Bu yöntemler doğru sonuçlar verebilmesine rağmen, özel ekipman veya uzmanlık gerektirir ve maliyeti yüksektir (Sanguinetti ve Posteraro, 2017; Wattal vd., 2017). Rutin olarak küflerin tanımlaması için gereken sürenin azaltılması gıda sektörünün yanı sıra klinik olarak hastalıklara çözüm bulunabilmesi açısından da önemlidir (Gautier vd., 2014). 200020000 Dalton'luk kütle aralığındaki ribozomal proteinlerin analizine dayanan Matriks ile desteklenmiş lazer desorpsiyon/iyonizasyon uçuş zamanı kütle spektrometresi (MALDI-TOF MS) yöntemi; bakteri, küf ve mayaları geleneksel yöntemlerle karşılaştırıldığında daha kısa bir süre içinde doğru bir şekilde tanımlamak için uygun bir yöntem olarak tanımlanmıştır (Wattal vd., 2017). Fourier Transform Infrared (FT-IR) spektroskopisi genellikle gida endüstrisinde ve bilimsel araştırmalar kapsamında şeker, asit vb. gibi kimyasal içeriğin belirlenmesi, gidaların bozulmasi, bakteri ve fungi gibi mikroorganizmları sayılarının belirlenmesinde ve tanımlanmasinda kullanılmaktadır (Kandpal ve Cho, 2014)

$\mathrm{Bu}$ çalışmada, küflerin geleneksel, moleküler, MALDI-TOF ve FT-IR gibi yöntemler ile tanımlanmasıyla ilgili yapılan çalışmaların araştırılması amaçlanmıştır. $\mathrm{Bu}$ çalışma kapsamında yöntemler, kullanılan cihaz gibi konular hakkında bilgi verilerek, yapılan çalışmalar derlenmiştir. 


\section{Küflerin Klasik/Geleneksel Yöntemler ile Tanımlanması}

Funguslar, dünyadaki en geniş organizma gruplarından biri olup, yapilan tahmini değerlendirmelere göre 1.5-3 milyon türü olduğu ifade edilmektedir. Moleküler yöntemlerin gelişmesi ile birlikte yaklaşık 100000 tanımlanmış tür bulunmaktadır. Gıda ve içecek endüstrisinde 50'sine sıklıkla rastlanmaktadır (Hawksworth, 2015). Fungal türlerin tanımlanması için en eski yöntem, başta üreme yapıları olmak üzere morfolojik özelliklerin belirlenmesidir. Fakat üreme yapısı geliştirmemiş fungal kültürler ya da farklı türlerin üyeleri arasındaki morfolojik benzerlikler nedeniyle tanımlamada sinırlamalar bulunmaktadır (Santos vd., 2010).

Gıdalarda bulunan küflerin tanımlanması için "Fungi and Food Spoilage" (Pitt ve Hocking, 2009) ve "Food and Indoor Fungi" (Samson vd., 2010) siklikla yararlanılan iki kitap olarak bilinmektedir. Araştırılan tür bu kaynaklarda bulunamazsa, daha geniş mikolojik literatürlere başvurmak gerekmektedir (Hawksworth, 2015). Hiflerin yapıs1, septa ve spor varllğı, spor şekli, boyutu, çap1 vb. gibi mikroskobik özellikler ile koloni görünümü (düz, balmumu, kadife, pamuk vb.), koloni büyüklüğ̈̈, koloni çap1, yüzeyin durumu (basık, kümelenmiş, çatlaklı vb.), yüzeyde ve besiyerinin altında görülen renk gibi makroskobik özellikler de incelenmektedir (Pitt ve Hocking, 2009).

Geleneksel yöntem kullanılarak küflerin tanımlandığı çalışmalar incelendiğinde bazılarında cins düzeyinde tanımlama yapılmısken, bazı çalışmalarda tür düzeyine kadar tanımlanmıştır. Küflü peynir yüzeyindeki küflerin izole edildiği ve morfolojik olarak tanımlandığı bir çalışmada Penicillium commune, Penicillium roqueforti ve Penicillium verrucosum türlerinin özellikle baskın olduğu bunun yanı sıra Geotrichum candidum, Penicillium expansum ve Penicillium chrysogenum'un da içinde bulunduğu 24 farklı türün tanımlandığ 1 rapor edilmiştir (Hayaloğlu ve Kırbağ, 2007). Taze bufalo sütü, yoğurt, tereyağ1 ve peynirde bulunan 21 cins ve 59 türe ait olan küflerin makroskobik ve mikroskobik özelliklerine bakılarak tanımlandığı çalışmada, tüm süt ürünlerinden izole edilen küflerin Aspergillus, Cladosporium, Mucor ve Penicillium'a ait olduğu rapor edilmiştir (Moubasher vd., 2018).

Çalışmalarda tüketime hazır gıdaların yanı sıra; ekipman, hava ve ambalaj gibi gıda ile temas eden ortamlarda küf analizleri yapilmakta ve bu küfler tanımlanabilmektedir. Peynir fabrikasında hava, plastik, salamura, süt ve ekipmanın örneklem olarak kullanıldığı çalışmadan alınan izolatlar tür düzeyinde tanımlanmış ve $P$. brevicompactum, Geo. candidum, $P$. commune, $P$. palitans, $P$. solitum, $P$. roqueforti türlerinin baskın olduğu belirlenmiştir (Kure vd., 2004). Mikroskobik ve makroskobik özelliklerin incelenerek küflerin tanımlandığı bazı benzer çalışmalar Çizelge 1'de belirtilmiştir.

Küflerin klasik yöntemle tanımlanması, ekim yapılmas1, inkübasyon süresi ve mikroskobik incelemeler nedeniyle zaman alıcı olup, sonuçlar gözlemlenen makromorfolojik ve mikromorfolojik karakterlerin yorumlanma şeklinden etkilenebilmektedir (Fischer vd., 2006). Biyokimyasal ve moleküler karakterlerin fungal taksonomiye dahil edilmesi, bu gibi problemleri çözmek için yardımcı olması adına önemli olmaktadır (Santos vd., 2010). Bir organizmanın karakterizasyonu için ne kadar fazla özellik kullanılırsa, yakından ilişkili türler daha doğru olarak ayırt edilebilmektedir (Fischer vd., 2006). Kültürel yöntemlerin yetersiz kaldığı durumlarda, moleküler tabanlı yöntemlerin kullanımı son yillarda yaygınlaşmıştır.

\section{Küflerin Moleküler Yöntemler ile Tanımlanması}

Mevcut fenotipik yöntemler tüm türlerin doğru bir şekilde ayırt edilebilmesi için elverişli değildir ve bu nedenle tanımlamada moleküler yöntemlere ihtiyaç duyulmaktadır (Criseo vd., 2015). Fenotipik olarak ayırt edilemeyen küf izolatları, ribozomal RNA (rRNA) veya diğer protein kodlayıc1 genlerin DNA dizi analizi ile tanımlanabilmektedir (Cassagne vd., 2011). Polimeraz Zincir Reaksiyonu (PZR) kullanılarak yapılan DNA tabanlı yöntem ile küflerin hızl, hassas ve spesifik olarak tespiti yapilabilmektedir (Jedidi vd., 2018). Funguslara ait genom dizisinin ilk olarak Neurospora crassa için Galagan vd. (2003) 
tarafindan belirlendiği, daha sonra Aspergillus nidulans, Aspergillus fumigatus ve Aspergillus oryza'nin genom dizilerinin belirlendiği ve karşılaştırıllığ1 rapor edilmiştir (Wakai vd., 2017). Gidalarda bulunan küflerin moleküler yöntemler ile tanımlanmasında PZR tekniği ve RNA dizi analizi (RNAseq) teknikleri kullanılmaktadır.
RNAseq tekniğinin kullanılabilmesi için yeterli miktarda ve saflıta küf RNA'sının gidadan izole edilmesi gerekmektedir. Bu kapsamda küf RNA's1 değişime uğramamış olmalı ve RNA izolasyonunu tehlikeye atabilecek proteinlerden, enzimlerden ve polisakkaritler gibi bileşiklerden arındırılmış olmalıdır (Bernáldez vd., 2017).

Çizelge 1. Küflerin makroskobik ve mikroskobik tanımlanmasına dair çalışmalar

\begin{tabular}{|c|c|c|}
\hline Gida & Tanımlanan küf & Referans \\
\hline Hindistan cevizi & A. flavus, A. niger, Rbizopus stolonifer, Penicilllium italicum & $\begin{array}{l}\text { Shehu ve Tafinta, } \\
2017\end{array}$ \\
\hline Kakao & $\begin{array}{l}\text { Aspergillus tamarii, A. niger, A. flavus, A. japonicus, } \\
\text { Fusarium chlamydosporum, Syncephalastrum racemosum }\end{array}$ & Fapohunda vd., 2018 \\
\hline Sucuk & $\begin{array}{l}\text { Scopulariopsis chartarum, Cladosporium cladosporioides, P. } \\
\text { jensenii }\end{array}$ & Çavuş vd., 2018 \\
\hline $\begin{array}{l}\text { Ananas, Karpuz, } \\
\text { Portakal, Papaya }\end{array}$ & $\begin{array}{l}\text { A. niger, Fusarium avenaceum, } P . \text { digitatum, } \\
\text { stolonifer, Fusarium solani }\end{array}$ & Mailafia vd., 2017 \\
\hline $\begin{array}{l}\begin{array}{l}\text { Misir’a özgü sert } \\
\text { peynir }\end{array}\end{array}$ & $\begin{array}{l}\text { A. ochraceus, A. alliaceus, A. oryzae, A. niger, A. nidulans, } \\
\text { A. flavus, A. glaucus, A. flavipes, Penicillium spp., Mucor } \\
\text { spp., R. stolonifer }\end{array}$ & El-Fadaly vd., 2015 \\
\hline Soğan & Aspergillus spp., Fusarium spp., Rbiropus spp. & $\begin{array}{l}\text { Ushasri ve Kumar, } \\
2018\end{array}$ \\
\hline Kirmız1 biber & $\begin{array}{l}\text { R. stolonifer, A. niger, Fusarium solanii, Alternaria alternata, } \\
\text { Geo. candidum, Mucor pusillus }\end{array}$ & $\begin{array}{l}\text { Fatimoh } \\
\text { vd., } 2017\end{array}$ \\
\hline Biberiye & Aspergillus sp., Cladosporium sp., Penicillium sp. & Garcia vd., 2018 \\
\hline
\end{tabular}

DNA bazlı yöntemler tür düzeyinde tanımlama sağlayan hassas bir metot olup, aynı zamanda taksonomik ve biyoçeşitlilik hakkındaki araştırmalara önemli katkılar sağlamaktadır (Dulla vd., 2016). Gidalarda bulunan küf biyoçeşitliliğinin belirlenmesinde ve taksonomik çalışmalarda her bir izolat için dizi analizlerinin yapılmasındansa, öncelikli olarak aynı olanların gruplandırılarak seçilen izolatlardan dizi analizi yapilmasi daha pratik ve ekonomiktir (Srivastava vd., 2017). Bu amaçla, Rastgele Çoğaltılmış Polimorfik DNA - Polimeraz Zincir Reaksiyonu (RAPD-PZR) ve Restriksiyon Parça Uzunluk Polimorfizmi - Polimeraz Zincir Reaksiyonu (RFLP-PZR) gibi moleküler belirteçler yaygın olarak kullanılmaktadır. RAPD-PZR yönteminde polimorfik DNA'nın seçilmiş bir primer ile rastgele çoğaltıldıktan sonra, agaroz jelde yürütülmesi ile elde edilen RAPD profillerinin görüntülenmesi suretiyle türler gruplandırlır
(Surženko vd., 2017). RFLP-PZR yönteminde ise, rDNA'nın ITS bölgeleri evrensel primer ile çoğaltılıp uygun restriksiyon enzimi ile kesildikten sonra jel elektroforezi ile bantlar görüntülenmektedir. Aynı bant görüntüsüne sahip izotlar gruplandırılmaktadır. Ruiz-Moyano vd (2009) tarafından yapılan çalışmada tütsülenmiş toz biberdeki küflerin RFLP-PZR yöntemi ile tür düzeyinde tanımlama için kullanılabileceği ifade edilmiş, ancak daha doğru tanımlama için ITS bölgelerinin dizi analizi yapılmıştır. RFLP-PZR yöntemi ile ayırt edilemeyen $P$. expansum, Penicillium griseofulvum veya Penicillium raistrickii olabileceği ifade edilen izolatların $P$. raistrickii olduğu dizi analizi ile doğrulanmıştır.

Çalışmalarda genellikle fungal patojenlerin tespitinde duyarlılığ arttırmak için evrensel fungal PZR primerleri geliștirilmektedir. DNA'nın PZR amplifikasyonu ve ardından elde edilen 
amplikonların dizilimi küfler için moleküler tanımlama adına en çok gelişme vaad eden yaklaşım olarak gösterilmektedir. Özellikle İnternal Ara Bölgeler (Internal Transcribed Spacer, ITS) bölgelerinin, küflerin filogenetik sınıflandırılması için faydalı olduğu belirtilmektedir (Raja vd., 2017). Fungusların tanımlanmasında, belirli bir izolatın kimliğini belirleyen bir DNA sekansını esas alan ve sıklıkla da nükleer ribozomal ITS'in evrensel fungal kısa bir DNA sekansinı (barkod) kullanan analizler uygulanmaktadir (Drissner ve Freimoser, 2017). Küflerin moleküler olarak tanımlanmasinda ribozomal (ITS1, ITS2 ve $26 \mathrm{~S}$ rRNA geninin D1/D2 bölgeleri) ve ribozomal olmayan ( $\beta$ tubulin ve EF1 $\alpha$ genleri) hedef bölgeler çoğaltılmaktadır (Panelli vd., 2012). ITS bölgesine dayanan tanımlama prosedürleri daha yaygın olarak kullanılmakta olup; ribozomal genin çoklu kopyalarının tüm organizmalarda bulunmas1 sebebiyle PZR ile hassas bir şekilde belirlenebilmesi, ITS bölgesindeki sekans değişkenliği ve yüksek oranda korunmuş olması nedeniyle yakından ilişkili türlerin ayrımına izin vermesi çalışmalarda ITS bölgelerinin tercih edilme sebepleri olarak bildirilmektedir (Trabelsi vd., 2019). Moleküler tanımlama veritabanında D1-D2 bölgesinden kapsaml olarak yararlanılmaktadır. D1-D2 bölgeleri bazen ITS1 veya ITS2 sonuçlarının doğrulanmasında kullanılmaktadır. Bazı çalışmalarda da özellikle ITS bölgeleri tercih edilmektedir; Pinheiro vd. (2011) tarafindan yapilan bir çalışmada benzer özelliklere sahip Aspergillus türlerinin tanımlaması genomun 25-28S bölgesinin D1-D2 bölgeleri yerine ITS dizileri kullanılarak elde edilmiştir. Yaklaşı 2500 tür hakkında referans dizileri bulunmaktadır. Ticari olarak bulunan DNA izolasyon kitleri ile miselyumdan ve sporlardan DNA ekstrakte edilebilmektedir (Hawksworth, 2015). Genomun standart bir bölümünden barkod elde edilip, bu sekansın referans barkod dizilerinden oluşan kütüphane ile karşılaştırılması sonucu tanımlama gerçekleşmektedir (Dulla vd., 2016). Moleküler yöntemler genellikle nükleik asitlerin sekanslarındaki farklılikların saptanmasina dayanmaktadır. PZR'in temel avantaj1, mikroorganizmaların kültüre edilmeden tanımlanabilmesidir. Genetik yöntemler ile hızlı bir şekilde ve spesifik olarak birbirine yakın türler arasında tanımlama yapılabildiği belirtilmiştir (Hertwig vd., 2018). Özdeş ITS sekanslarının, Aspergillus'un bazı türlerinde olduğu gibi iki veya daha fazla farklı tür tarafindan paylaşılabileceği göz önünde bulundurulmalıdır (Hawksworth, 2015). Bu nedenle farklı primerler kullanilarak tanımlamalar doğrulanmaktadır. Küflerin tanımlanmasinda kullanılan DNA dizi analizlerinin bazı dezavantajları da bulunmaktadır. Küf kültürlerinin lize edilmesi nispeten zor olduğu için DNA ekstraksiyon verimi az olabilmekte, ayrıca PZR amplifikasyonu, küf kültürlerinde PZR inhibitörlerinin varlığından dolayı başarısız olabilmektedir (Cassagne vd., 2011). Moleküler tanımlamada fazla veri üretilmesi ve bu verilerin depolanması genellikle sınırlayıc1 bir durumdur, aynı zamanda DNA dizilimleri için kütüphanelerinin hazırlanması ve kalite kontrolü zaman alıc1 ve masraflı olabilmektedir (Drissner ve Freimoser, 2017).

Garnier vd. (2017) tarafindan yapılan araştırmada, tereyağ1, krema, peynir, yoğurt örneklerinden ve üretim ortamlarından alınan toplam 175 izolatta ITS4, ITS5, Bt2a, Bt2b, EF1-728F, EF1-986R, cmd5, cmd6 primerleri kullanılarak tanımlanan küflerden P. commune, Penicillium bialowiezense'e en çok rastlanırken, Penicillium antarticum, Penicillium salamii, Cladosporium phyllophilum süt ürünlerinde ilk defa tanımlanmıştır. Kurutulmuş balık örneğinden izole edilen küflerin moleküler olarak tanımlandığı çalışmada, dizi analizi sonucunda kurutulmuş balıklarda Aspergillus flavus, A. nidulans, A. oryzae, A. sydowii, A. rugulosa, A. niger, A. foetidus, Lichtheimia ramosa ve Curvularia lunata'nın bulunduğu rapor edilmiştir (Sivaraman vd., 2018).

Genellikle içecekler ile temas eden buz küplerindeki küflerin incelendiği çalışmada bütün örneklerde küf tespit edilmiştir. Seçilen kolonilerin fenotipik ve genotipik karakterizasyonu belirlenirken 9 küf izolat1 moleküler olarak tanımlanmıştır. ITS1/ITS4 primerleri kullanılarak tanımlanan küfler; Fusarium spp., Fusarium solani, Hansfordia spp. Paecilomyces spp., Paecilomyces lilacinus, Penicillium glabrum, Phoma leveillei, Purpureocillium spp., Thanatephorus cucumeris olarak rapor edilmiştir (Francesca vd., 2018). 
Diğer bir çalışmada, farklı moleküler yöntemler uygulanmış ve 39 izolatın 16 farklı suştan oluştuğu rapor edilmiş, RAPD-PZR analizi ile elde edilen profillerin, Geo. candidum'un tür içinde ayrilmasında ve farklı türlerin suş düzeyinde karakterizasyonu için kullanılmasına uygun olduğu bildirilmiştir (Sacristán vd., 2013).

Çavdar ekmeklerinin bir ay boyunca plastik ambalajda tutulduğu ve ekmek yüzeylerinden farklı morfolojiye sahip küflerin izole edildiği çalışmada, RAPD-PZR yöntemi ile M13 primeri kullanılarak 50 fungal izolat elde edilmiş ve tanımlanmıştır. Tanımlanan küfler Aspergillus chevalieri, A. flavus/oryzae, A. niger, Aspergillus tubingensis, Penicillium citrinum, P. corylophilum olarak rapor edilmiştir. $\beta$-tubulin geninin ve ITS bölgesinin dizilişi, Penicillium türlerinin tanımlanması için eşit bir etkinlik gösterirken, sadece $\beta$-tubulin geninin sekans1, benzer özellikteki Aspergillus türleri de dahil olmak üzere çoğu izolatın tanımlanmasını sağlamıştır (Surženko vd., 2017).

Zhao vd. (2018)'in araştırmasında, topraktan izole edilen küfün koloni görünüşü, dokusu, rengi gibi morfolojik özellikleri CYA (Czapek Yeast Agar) ve MEA (Malt Extract Agar) besiyerinde, ardından spor yapılarını gözlemlemek için de mikroskop altında incelenmiştir. Suş, daha sonra Aspergillus için taksonomik kılavuzlar kullanılarak tanımlanmıştır. ITS, $\beta$-tubulin ve kalmodulin genleri baz alınarak moleküler olarak da tanımlanmış ve suşun Aspergillus tubingensis QF05 olduğu rapor edilmiştir.

244 izolatın sekans analizinin yapıldığı çalışmada ise, 19 izolatın ITS verileri elde edilemediği için 225 izolat için fenotipik yöntem ile sekans analizi karşılaştırılmıştır. Fenotipik tanımlama ile sekans bazlı karşılaştırmada, sekans analizinin, izolatların $\% 52$ 'sinde daha kesin sonuçlar verdiği, izolatların \%38.60'ında, her iki yöntemin de sonuçlarının uyumlu olduğu rapor edilmiştir (Ciardo vd., 2007). Diğer bir çalş̧mada, Cabrales İspanyol peynirinin olgunlaşması sırasında baskin olan küfler morfolojik ve genotipik olarak tanımlanmıs, çalışmada morfolojik olarak 12 izolat Penicillium spp., 11 izolat Penicillium roqueforti, 10 izolat Geo. candidum, 1 adet Acremonium charticola'nın tanımlandığ1 ve tanımlanamayan bir izolatın olduğu rapor edilmiştir. ITS bölgelerinin kullanıldığ moleküler analizde, Penicillium türlerinin 5 adeti $P$. commune, 4 adeti $P$. chrysogenum, 2 adeti P.roqueforti ve 1 adeti $P$. citreonigrum olarak tanımlanmıştır (Flórez vd., 2007). Çizelge 2'de gidalardan izole edilen küflerin moleküler yöntemler ile tanımlanmasinda kullanilan primerler ve tanımlanan küfler özetlenmiştir.

\section{Küflerin MALDI-TOF Yöntemi ile Tanımlanması}

Proteomik analiz, hücresel proteinlerin küresel değerlendirmesi olarak tanımlanmaktadır (Kim vd., 2007). Son y1llarda, kromatografik ve hatta DNA'ya bağlı metotlara alternatif olarak, proteomik yaklaşım kullanılarak mikrobiyel türün tanımlanmasını hedefleyen yöntemlerden olan MALDI-TOF MS yöntemi, her fungal taksonun karakteristik bir spektrumunu üretmek için mikoloji alanında uygulanmaktadır (Oliveira vd., 2015; Panda vd., 2015). MALDI-TOF MS 1980'lerde geliştirilmiş olup, moleküllerin iyonlaşmasıyla organik bileşiklerin molekül kütlelerini belirlemek için yapılmaktadır (Miguel vd., 2017). MALDI-TOF MS'de bütün veya parçalanmış proteinler, kristalize matris varllğında bir lazer ile iyonize edilerek elektrik alana tabi tutulmaktadır (Kim vd., 2007). Bu yöntem 200020000 Dalton kütle aralığındaki proteinlerin ölçümüne dayanan tekrarlanabilir bir yöntemdir (Oliveira vd., 2015). MALDI-TOF MS, bakteri ve küf-mayaları birkaç dakika içinde doğru bir şekilde tanımlayabilen bir yöntemdir (Wattal vd., 2017). Tanımlama, protein dizisinin veritabanındaki teorik peptitler ile karşılaştırılmasına (hücrelerin peptit kütle parmak izlerine, peptide mass fingerprints) dayanmaktadır (Kim vd., 2007; Lüthje vd., 2017). Fungusların kütle spektrometrik peptid/protein profilleri, 100020000 m/z (kütle/yük) bölgesindeki moleküler iyon pikleri verir; burada biyomarker iyonlarının oluşturduğu set, örneklerin cins, tür veya suş seviyesinde farklılaşmasını kolaylaştırmaktadır (Chalupová vd., 2014). Referans spektrumlarla eşleşen ve mikroorganizmanın tanımlanmasını sağlayan her mikroorganizma için tipik bir 
spektrum (MS parmak izi) oluşturulmaktadır (Panda vd., 2015).

Çizelge 2. Küflerin moleküler olarak tanımlanmasına dair çalışmalar

\begin{tabular}{|c|c|c|c|c|}
\hline Gida & Moleküler yöntem & $\begin{array}{l}\text { Kullanilan } \\
\text { Primerler }\end{array}$ & Tanımlanan Küfler & Referans \\
\hline \multirow[b]{2}{*}{$\begin{array}{l}\text { Çavdar } \\
\text { ekmeği }\end{array}$} & RAPD-PCR & M13 & \multirow[b]{2}{*}{$\begin{array}{l}\text { Aspergillus chevalieri, } A . \text { flavus, } A . \text { niger, } A . \\
\text { tubingensis, } P . \text { citrinum, } P . \text { corylophilum }\end{array}$} & \multirow[b]{2}{*}{$\begin{array}{l}\text { Surženko } \\
\text { vd., } 2017\end{array}$} \\
\hline & $\begin{array}{l}\beta \text {-tubilin geni dizi } \\
\text { analizi }\end{array}$ & $\mathrm{Bt} 2 \mathrm{a}, \mathrm{Bt} 2 \mathrm{~b}$ & & \\
\hline \multirow{2}{*}{$\begin{array}{l}\text { Armada } \\
\text { peyniri }\end{array}$} & RAPD-PCR & M13 & \multirow[b]{2}{*}{ Geo. candidum, Geo. candidus } & \multirow{2}{*}{$\begin{array}{l}\text { Sacristán } \\
\text { vd., } 2013\end{array}$} \\
\hline & $\begin{array}{l}\text { ITS1-5.8S-ITS2 } \\
\text { bölgesi dizi analizi }\end{array}$ & ITS4, ITS5 & & \\
\hline $\begin{array}{l}\text { Tütsülenmiş } \\
\text { domuz } \\
\text { pastırması }\end{array}$ & $\begin{array}{l}\text { ITS1-5.8S-ITS2 } \\
\text { bölgesi dizi analizi }\end{array}$ & ITS1, ITS2 & $\begin{array}{l}\text { Cladosporium oxysporum, Cladosporium } \\
\text { cladosporioides, Cladosporium herbarum }\end{array}$ & $\begin{array}{l}\text { Alía vd., } \\
2016\end{array}$ \\
\hline Fistik & $\begin{array}{l}\text { ITS bölgesi dizi } \\
\text { analizi }\end{array}$ & ITS1, ITS4 & $\begin{array}{l}\text { A. flavus, A. tamarii, A. niger, Macrophomina } \\
\text { phaseolina, Penicillium spp. }\end{array}$ & $\begin{array}{l}\text { Jogee vd., } \\
2017\end{array}$ \\
\hline Parmesan & $\begin{array}{l}\text { ITS1-5.8S-ITS2 } \\
\text { bölgesi dizi analizi }\end{array}$ & ITS1, TW13 & $\begin{array}{l}\text { C. cladosporioides, P. verrucosum, P. roqueforti, } \\
\text { P. camemberti }\end{array}$ & $\begin{array}{l}\text { Banjara } \\
\text { vd., } 2015\end{array}$ \\
\hline $\begin{array}{l}\text { Sofralik } \\
\text { zeytin }\end{array}$ & $\begin{array}{l}\beta \text {-Tubulin ve ITS } \\
\text { bölgeleri dizi analizi }\end{array}$ & $\begin{array}{l}\text { ITS4/ITS5, } \\
\text { Bt2a/Bt2b }\end{array}$ & $\begin{array}{l}P . \text { crustosum, } P . \text { roqueforti, } P . \text { paneum, } P . \\
\text { expansum, } P \text {. polonicum, } P \text {. commune }\end{array}$ & $\begin{array}{l}\text { Bavaro } \\
\text { vd., } 2017\end{array}$ \\
\hline $\begin{array}{l}\text { Tütsülenmiş } \\
\text { sosis }\end{array}$ & $\begin{array}{l}\beta \text {-Tubulin ve ITS1- } \\
5.8 S-I T S 2 \\
\text { bölgeleri dizi analizi }\end{array}$ & $\begin{array}{l}\text { Bt2a, Bt2b, } \\
\text { ITS1, ITS4 }\end{array}$ & C. cladosporioides, Cladosporium uredinicola & $\begin{array}{l}\text { Lozano- } \\
\text { Ojalvo } \\
\text { vd., } 2015 \\
\end{array}$ \\
\hline \multirow{2}{*}{$\begin{array}{l}\text { Tütsülenmiş } \\
\text { toz biber }\end{array}$} & PZR-RFLP & ITS1, ITS4 & \multirow{2}{*}{$\begin{array}{l}\text { A. flavus, } A \text {. ochraceus, } A \text {. niger, } \\
\text { Fusarium oxysporum, } P \text {. raistrickii }\end{array}$} & \multirow{2}{*}{$\begin{array}{l}\text { Ruiz- } \\
\text { Moyano } \\
\text { vd., } 2009\end{array}$} \\
\hline & $\begin{array}{l}\text { 5.8S-ITS bölgesi dizi } \\
\text { analizi }\end{array}$ & ITS4, ITS5 & & \\
\hline Şeker kamışı & PZR-RFLP & ITS4, ITS5 & $\begin{array}{l}\text { Colletotrichum falcatum, Fusarium moniliforme, } \\
\text { Trichoderma viride }\end{array}$ & $\begin{array}{l}\text { Srivastava } \\
\text { vd., } 2017\end{array}$ \\
\hline \multirow[t]{2}{*}{ Ananas } & PZR-RFLP & $\begin{array}{l}\text { ITS1, ITS4, } \\
\text { ITS5 }\end{array}$ & \multirow{2}{*}{$\begin{array}{l}\text { Aspergillus aculeatus, Rhizopus oryzae, Geo. } \\
\text { candium, Neurospora tetrasperma }\end{array}$} & \multirow{2}{*}{$\begin{array}{l}\text { Fulgence } \\
\text { vd., } 2019\end{array}$} \\
\hline & Dizi analizi & ITS1, ITS4 & & \\
\hline \multirow[b]{2}{*}{ İncir } & PZR-RFLP & ITS1, ITS4 & \multirow{2}{*}{$\begin{array}{l}\text { C. cladosporioides, Penicillium corylophilum, } A \text {. } \\
\text { alternata }\end{array}$} & \multirow[b]{2}{*}{$\begin{array}{l}\text { Villalobos } \\
\text { vd., } 2017\end{array}$} \\
\hline & $\begin{array}{l}\text { ITS1-5.8S-ITS2 } \\
\text { bölgesi dizi analizi }\end{array}$ & ITS1, ITS4 & & \\
\hline
\end{tabular}

MALDI-TOF MS metodolojisi nispeten az sayıda $\left(10^{6}-10^{7}\right)$ mikrobiyel hücre gerektirir (Oliveira vd., 2015). Tanımlanacak örneği cihaza yerleştirmeden önce proteinlerin elde edilmesi için gerçekleşen ekstraksiyon prosedürü çalışmadan çalışmaya değişiklik gösterebilmektedir. Genel olarak küf üremesi tamamlandıktan sonra bulaşmaları önlemek için etanol içerisinde bekletilerek küfler inaktive edilmekte ve ardindan proteinlerin elde edilmesi için asetonitril ve formik asit içeren solüsyon uygulanmaktadır (Luethy ve Zelazny, 2018). Numune hazırlama prosedürü, uygun bir matris bileşiği seçimi, numune yerleştirme teknikleri gibi işlemlerde bu özelliklerin dikkate alınarak çeşitli yaklaşımların geliştirilmesi mümkün olmaktadır (Chalupová vd., 2014).
Numune ekstraksiyon prosedürüne yeterli dikkat gösterilerek ve referans kütüphanedeki her bir türü temsil eden kütle spektrumlarının sayısı arttırlarak MALDI-TOF'un küflerin tanımlamasında kullanımı geliştirilebilmektedir (Angeletti, 2017).

MALDI-TOF MS platformlar1 2004'ten beri, farklı ticari firmalar tarafindan piyasaya sürülmektedir. MALDI-TOF MS kullanılarak küflerin tanımlanmasi, bakteri ve maya tanımlamalarından daha zor olup, küf kolonileri spor, miselyum gibi farklılaşmış yapilardan oluştuğu için tekrarlanabilir spektrumların elde edilmesini engellemektedir (Cassagne vd., 2016). Küf izolatlarında hif ve konidial yapılar bir arada 
bulunabildiği için küflerin MALDI-TOF MS spektrumları yavaş elde edilebilmektedir. $\mathrm{Bu}$ yüzden bir fungal izolattan üretilen MALDI-TOF spektrumu, referans veri tabanındaki spektrum ile her zaman tamamıyla eşleşemeyebilmektedir (Angeletti, 2017). Bakteri tanımlaması oldukça ilerlemiş olmasina rağmen diğer mikroorganizmalarin biyotiplendirilmesi hala gelişme aşamasındadır (Stübiger vd., 2016). MALDI-TOF MS klinik laboratuvarlarda patojenlerin doğru, hizlı ve ekonomik tanımlanması için standart bir araç haline gelmiştir. $\mathrm{Bu}$ yüzden metot sürekli olarak iyileştirilmekte ve suşların ayırt edilmesi, metabolitlerin veya antibiyotik direnci gibi fonksiyonel karakteristiklerin belirlenmesi için sürekli yeni uygulamalar geliştirilmektedir. Bunun yanı sıra tarım, gida güvenliği ve kalite testleri veya ekoloji alanı gibi disiplinlerde de bu yöntemin benimsenmesi için araştırmalar yapılmaktadır (Drissner ve Freimoser, 2017). Maliyet etkinliği, kısa analiz süresi, düşük hata oranı ve aynı zamanda yakın ilişkili türler arasında ayrım yapabilme özelliği MALDI-TOF'u rutin analizlerde kullanilmaya uygun hale getirmektedir. Tekniğin dezavantaj1, kültürlerin önceden izole edilmiş ve saflaştırılmış olması olup, gida vb. matrikslerde direkt olarak uygulanamamasidır (Hendrickx, 2017).

MALDI-TOF MS kullanılarak 88 maya ve 37 küf izolatının tanımlandığı bir çalışmada, MALDITOF MS ile klasik tanımlama arasındaki korelasyon tüm izolatlar (125) için cins seviyesinde $\% 90.40$ ve tür seviyesinde $\% 87.20$ olarak bildirilmiştir. MALDI-TOF MS ile küflerin $\% 10.81$ 'inin cins seviyesinde, $\% 56.70$ 'sinin de cins ve tür seviyesinde tanımlandığı da rapor edilmiştir. Numune hazırlama protokolünde yapılan değişiklik ile belirlenen yüzdelerin cins ve tür bazındaki tanımlama yüzdesi $\% 86.40$ olarak iyileştirilmiştir. Numune hazırlığından başlayarak tanımlamaya kadar geçen toplam sürenin 23 dakika olması araştırmacılar tarafindan diğer yöntemlere alternatif bir özellik olarak belirtilmektedir (Panda vd., 2015).

Gidalarda siklikla rastlanan Aspergillus spp., Penicilium spp., Mucor spp. ve Fusarium spp.'nin arasında olduğu ve standart bir ekstraksiyon protokolünün uygulandığ1 çalışmada, 136 türe ait 618 fungal suştan 6477 spektrum elde edilmiştir. Veritabanı kullanılarak çapraz değerlendirilmiş ve $\% 95$ oranında türlerin doğru tanımlandığı rapor edilmiştir. Araştırmacılar MALDI-TOF yönteminin geleneksel yöntemlere alternatif olacağını bildirmektedir (Quéro vd., 2018).

Yapılan bir çalışmada, 262 izolatın tanımlanması için 347 türe ait 708 suşa karş1llk gelen 2832 referans spektrumunu içeren referans spektrum kütüphanesi kullanılarak ulaşılan MALDI-TOF MS verileri, morfolojik olarak ve DNA bazlı tanımlama ile karşılaştırılmıştır. Çalışmada $A$. fumigatus, $A$. flavus, $A$. niger ve Aspergillus terreus en s1k rastlanan 4 tür olarak bildirilmiş ve DNA sekansina dayalı tanımlama, on izolattan sadece biri üzerinde gerçekleştirilmiştir. MALDI-TOF MS'nin uygulanmas1, küflerin tanımlanma düzeyini tür seviyesinde $\% 78.20$ den $\% 98.10^{\prime}$ a çıkarmış ve eksik tanımlama oranını $\% 9.80$ 'den $\% 1.20$ 'ye düşmesini sağlamıstır. MALDI-TOF MS ile 24 izolatın analizi için gereken sürenin yaklaşık 95 dakika olduğu bildirilmiştir. Morfolojik olarak tanımlamada gereken özelliklerin görülemediği genç kolonilerin MALDI-TOF MS ile doğru bir şekilde tanımlanabildiği rapor edilmiştir (Gautier vd., 2014). Geleneksel tanımlamanın MALDI-TOF MS ile karşılaştırıldığı diğer bir çalışmada 58 türü içeren 625 küf izolatının, 501'inin (\% 80) geleneksel olarak, 556'sının da (\% 89) MALDITOF MS ile doğru olarak tanımlandığ belirlenmiştir. Aynı çalışmada, Aspergillus dışındaki türlerin tanımlanmasinda, geleneksel yöntemle \%30.6 oranında doğru tanımlama sağlanırken, MALDI-TOF yöntemi ile ise doğru tanımlama oranının \%61.2 olduğu bildirilmiştir (Ranque vd., 2014).

MALDI-TOF MS ile 12003 izolatın tanımlandığ çalışmada, bakteri suşları için $\% 97.70$, mayalar için $\% 92.80$ ve küfler için de $\% 80$ oranında tanımlama gerçekleşmiştir. Aspergillus fumigatus, A. flavus, $A$. oryzae, $A$. terreus, Fusarium solanir ye ait 20 izolattan 16's1 tanımlanabilmiştir. Veri tabanlarında bulunmayan spektrumlar, kültürel koşullar, protein ekspresyonunun değişkenliği, iç kalibrasyonun başarısızlığ1 ve benzer proteinleri 
ifade eden yakın ilişkili türlerin hatalara ya da hatalı tanımlamaya yol açabildiği araştırmacılar tarafindan belirtilmiştir (Wattal vd., 2017).

Küflerin tanımlanması için MALDI-TOF MS yönteminin kullanımındaki sınırlamalarından en önemlisi ticari olarak temin edilebilen veritabanlarının geniş olmamasıdır. Genişletilmiş MALDI-TOF MS veritabanlarının oluşturulması, emek ve mikolojik beceri gerektirmektedir. $\mathrm{Bu}$ nedenle, küfler için referans veri tabanını, veritabaninda temsil bulunmayan rutin numune kültürlerinden türetilen küf türleri ile zenginleştirerek sürekli olarak güncellemek gerekmektedir. Yetersiz MALDI-TOF MS tanımlama sonuçlarının, referans veri tabanı oluşturma prosedürleri ile izolatların kütle spektrumunu elde etmek için olan prosedürler arasındaki farklilıklardan kaynaklandığ bildirilmiştir (Sanguinetti ve Posteraro, 2017).

\section{Küflerin FT-IR ile Tanımlanması}

FT-IR, bir moleküldeki kimyasal bağ türlerini tanımlamak için kullanılan eski bir teknik olup, günümüzde dijitalleşmesiyle de kullanım açısından kolaylık sağlanmıştır (Santos vd., 2010). Endüstri, araştırma ve tıp bilimi gibi çoğu alanda FT-IR spektrometrelerin uygulamaları mevcuttur. Çok miktarda veri kısa sürede yüksek hassasiyetle analiz edilebilmektedir. FT-IR spektrometresi polimerlerin tanımlanmasında, hammaddelerin bileşiminin doğrulanmasında, yüzey analizlerinde, mikroorganizmaların tanımlanmasında, adli bölümlerde, kalite kontrol taramasında, biyomedikal alanında olmak üzere birçok alanda kullanilmakta olup, bu konuda ilerlemeler devam etmektedir (Vij, 2007). Gidalarda bulunan mikroorganizmaların tanımlanmasi, makromoleküllerin yapısal analizi, organik maddelerin kalitatif ve kantitatif analizi, maddelerin yapilarının aydınlatılması ve saflık kontrolü gibi birçok alanda FT-IR spektroskopisi kullanılmaktadır (Büyüksırıt ve Kuleaşan, 2014).

Fenotipik ve genotipik yöntemlere dayalı fungusların rutin tanımlanması titiz çalışma gerektirmekte ve zaman alıcı olabilmektedir. FTIR spektroskopisi küflerin hızlı bir şekilde tanımlanmasına olanak tanıyan yaklaşımlardandır
(Lecellier vd., 2014). FT-IR'in temeli, bir numunedeki moleküller tarafindan kızılötesi 1şığın absorbe edilmesidir. Kızılötesi 1şınları absorbe edildiğinde, molekül içindeki saptanabilir dipol değişikliklerinin her biri, kimyasal yapılarına bağlı olarak belirli frekans bölgelerinde gözlemlenebilmektedir (Oberle vd., 2015). Işın, numunedeki ışınlanan enerjinin miktarını kontrol etmek için bir odayı geçer. Kızılötesi 1şını, spektral kodlamanın gerçekleştiği interferometreye girer; sonuçtaki interferogram sinyali interferometreden çıkar. Son olarak, ışın son ölçüm için dedektöre geçer ve ölçülen sinyal dijitalleştirilirek, Fourier dönüşümünün gerçekleştiği bilgisayara gönderilmektedir. Böylelikle spesifik "parmak izi" ifade etme kapasitesi sayesinde FT-IR spektroskopisinin spektral veri kütüphaneleri kullanarak bilinmeyen mikrobiyel suşların tanımlanması için kullanılmasına olanak tanımaktadır (Santos vd., 2010). İçeceklerden ve üretimde kullanılan ekipmanlarda tanımlanan küflerin, FT-IR ile karakterizasyonunun yapıldığ çalışmada Alternaria, Aspergillus, Mucor, Paecilomyces ve Phoma'ya ait türlerin spektrumları elde edilmiştir (Shapaval vd., 2010).

Fransa ve Hollanda'da bulunun iki kültür koleksiyonundan temin edilen ve DNA dizilimi kullanılarak tanımlanan 131 suş için FT-IR spektroskopisi kullanılan bir çalışmada, elde edilen tanımlama seviyeleri cins bazında \%98.97 ve tür bazında \%98.77 olarak bildirilmiştir (Lecellier vd., 2014). Araştırmacıların diğer çalışmalarında ise, yine aynı iki kültür koleksiyonundan temin edilen 486 küf suşunun (43 cins ve 140 tür) önceden oluşturulan spektral veri tabanı kullanılarak FT-IR spektrumları belirlenmiştir. Elde edilen spektrumların $\% 99.17$ 'sinin cins ve \%92.30'unun tür seviyesinde doğru tanımlandığ1 bildirilmiştir. Çalışma sonucunda, küflerin hizlı ve doğru olarak tanimlanmasinda FT-IR spektroskopisinin alternatif bir yöntem olarak kullanılabileceği rapor edilmiştir (Lecellier vd., 2015).

Gıda üretim hattı boyunca farklı kontrol noktalarından alınan numunelerden mikroorganizmaların izolasyonu ve saflaştırılmasının ardından besiyerinde 
mikroorganizmaların geliştirilmesi ve üreme gösteren mikroorganizmaların mikroplakalarda geliştirilmesinden sonra FT-IR spektroskopisi aracilığılla veri kütüphanelerinden yararlanılarak mikroorganizmaların tanımlanmasının mümkün olabileceği bildirilmiştir. Gıda üretim hattından Alternaria, Aspergillus, Mucor, Paecilomyces, Peyronellaea ve Phoma'ya ait 20 adet küfün referans olarak seçildiği çalışmada, seçilen izolatların FTIR spektroskopisi ile \%80-100 aralığında doğruluk ile tanımlanabildiği rapor edilmiştir (Shapaval vd., 2017).

Genellikle bitkilerin bozulmasina neden olan Fusarium spp. ve Pythium spp.'ye ait toplam 20 türün FT-IR spektroskopisi ile incelendiği çalışmada analiz edilen küflerin her biri için tutarlı spektrumlar elde edilmiştir. 1800-1000 $\mathrm{cm}^{-1}$ arasında değişen spektral alanda küfler arasında 1 saatte kolay ve güvenilir bir tanımlama sağlandığ1 rapor edilmiştir. FT-IR spektroskopisinin uygulanabilir, doğru ve hassas bir yöntem olduğu bildirilmiştir (Erukhimovitch vd., 2005).

FT-IR, mikroorganizmalar gibi kimyasal olarak çok kompleks yapıların kompozisyonunu karakterize etmek için kullanılabilmektedir. Metabolit üretiminde farklilık gösteren bir taksonun suşları FT-IR spektroskopisi ile güvenilir şekilde ayırt edilebilmektedir. $\mathrm{Bu}$ yöntemin Aspergillus ve Penicillium türlerini, tür ve suş seviyesinde tekrarlanabilir bir şekilde ayırt etmek için uygun olduğu bildirilmektedir (Fischer vd., 2006). Mikrobiyolojik FT-IR hızlı, etkili, reaktif içermez, tüm mikroorganizmalar için geçerlidir ve az miktarda biyokütle gerektirmektedir (Santos vd., 2010).

Küflerin mikroskobik ve makroskobik özelliklerini içeren klasik yöntemlerle tür düzeyinde tanımlanması oldukça zordur. Bifazik tanımlama olarak ifade edilen morfolojik, kimyasal ve moleküler özelliklerin birleştirilmesi ile elde edilen sonuçların kesin ve güvenilir olduğu belirtilmiştir (Decontardi vd., 2018). Küflerin tanımlanmasında kullanılan geleneksel yöntemler, moleküler yöntemler, MALDI-TOF MS ve FT-IR yöntemlerinin çeşitli avantaj ve dezavantajları bulunmaktadır (Çizelge 3).

Çizelge 3. Küflerin Tanımlanmasında Kullanılan Yöntemlerin Karşılaştırılması (Büyüksırıt ve Kuleaşan, 2014; Cassagne vd., 2011; Lecellier vd., 2015; Jedidi vd., 2018)

\begin{tabular}{|c|c|c|}
\hline Yöntem & Avantaj & Dezavantaj \\
\hline Geleneksel yöntem & -Maliyeti düşüktür & $\begin{array}{l}\text {-Deneyimli personele ihtiyaç duyulmaktadır. } \\
\text {-Zaman alıcıdır. } \\
\text {-Hassasiyeti düşük olup, tür düzeyinde } \\
\text { tanımlanması zordur. }\end{array}$ \\
\hline Moleküler yöntemler & $\begin{array}{l}\text {-Hizlı, hassas ve tür düzeyinde } \\
\text { spesifik } \\
\text { yapılabilmektedir. }\end{array}$ & $\begin{array}{l}\text {-DNA veya RNA ekstraksiyonlarında } \\
\text { sikıntılar yaşanabilmektedir. } \\
\text {-Maliyeti yüksektir. } \\
\text {-Emek yoğundur. }\end{array}$ \\
\hline MALDI-TOF & $\begin{array}{l}\text {-Basit, hızlı ve doğru sonuç alınır. } \\
\text {-Makine yatırımı yapıldıktan sonra } \\
\text { izolat başına maliyeti çok düşüktür. } \\
\text {-Hata oranı düşüktür. } \\
\text {-Yakın ilişkili türler arasında ayrım } \\
\text { yapabilir. } \\
\text {-Deneyimli personele gerek yoktur. }\end{array}$ & $\begin{array}{l}\text {-Geniş aralıktaki küflerin tanımlanması için } \\
\text { veritabanı yetersiz kalmaktadır. } \\
\text {-Kültürler önceden izole edilmiş ve } \\
\text { saflaştırılmış olmalı, gıda vb. matrikslerde } \\
\text { direkt olarak uygulanamaz. } \\
\text {-Makine maliyeti yüksektir. }\end{array}$ \\
\hline FT-IR & $\begin{array}{l}\text {-Hızlı ve etkilidir. } \\
\text {-Reaktif kullanımına gerek yoktur. }\end{array}$ & $\begin{array}{l}\text {-Geniş aralıktaki küflerin tanımlanması için } \\
\text { veritabanı yetersiz kalmaktadır. }\end{array}$ \\
\hline
\end{tabular}




\section{SONUÇ}

Gıdalardaki küflerden kaynaklanabilecek risklerin azaltılması, küf bulaşma kaynaklarının belirlenmesi ve mikotoksin üreten küflerin belirlenebilmesinin yanında, antibiyotik, renk pigmentleri, organik asit vb. ürünlerin üretiminde kullanılabilmesi için küflerin doğru bir şekilde tanımlanmaları önem arz etmektedir. Küflerin koloni morfolojisi ve mikroskobik özelliklerin incelenmesine dayalı klasik yöntemler tanımlamada tek başına yeterli değildir. Tanımlama işlemi, uzman laboratuvarda ve deneyimli kişiler tarafından yapilması gereken hassas ve emek gerektiren zaman alıcı bir süreçtir. Gıdalarda bulunan küflerin çok geniş bir çeşitlilik göstermesi nedeniyle, kültürel yöntemlerle tür düzeyinde tanımlama yapılması deneyimli personel ile bile çoğu zaman mümkün olmamaktadır, bu nedenle günümüzde küflerin tanımlanmasında moleküler yöntemlerin kullanılması zorunlu hale gelmiştir. Geleneksel mikolojik tekniklere ek olarak yararlanılan moleküler tabanlı ve proteomik yöntemler son zamanlarda geliştirilmeye devam etmektedir. Bunlardan bazıları basit PZR tabanlı yöntemler, gerçek zamanlı PZR, MALDI-TOF ve FT-IR gibi yöntemlerdir. Klasik yöntemlere ek olarak geliştirilen bu yeni yöntemler sayesinde bilimsel, endüstriyel ve halk sağlı̆̆ı açısından da önemli olacak gelişmeler söz konusudur. Yeni yöntemler ile birlikte daha hızlı ve doğru sonuçlar ortaya konmaktadır. Buna rağmen optimizasyon süreci tamamlanana kadar çalşmalarda geleneksel yöntem, yeni yöntemler ile karşllaştırılarak ve/veya desteklenerek daha kesin sonuçlara ulaşılmaktadır.

\section{KAYNAKLAR}

Alía, A., Andrade, M.J., Rodríguez, A., ReyesPrieto, M., Bernáldez, V., Córdoba, J.J. (2016). Identification and control of moulds responsible for black spot spoilage in dry-cured ham. Meat Sci 122: 16-24, doi: 10.1016/j.meatsci.2016.07.007.

Angeletti, S. (2017). Matrix assisted laser desorption time of flight mass spectrometry (MALDI-TOF MS) in clinical microbiology. $J$ Microbiol Methods 138: 20-29.
Banjara, N., Suhr, M.J., Hallen-Adams, H.E. (2015). Diversity of yeast and mold species from a variety of cheese types. Curr Microbiol 70(6): 792800.

Bavaro, S.L., Susca, A., Frisvad, J.C., Tufariello, M., Chytiri, A., Perrone, G., Mita, G., Logrieco, A.F., Bleve, G. (2017). Isolation, characterization, and selection of molds associated to fermented black table olives. Front Microbiol 8: 1356, doi: 10.3389/fmicb.2017.01356.

Bernáldez, V., Rodríguez, A., Rodríguez, M., Sánchez-Montero, L., Córdoba, J.J. (2017). Evaluation of different RNA extraction methods of filamentous fungi in various food matrices. LWT-Food Sci Technol 78: 47-53.

Bhunia, A.K. (2018). Molds and Mycotoxins. In: Foodborne Microbial Pathogens, Springer, New York, NY, pp. 167-174.

Büyüksır1t, T., Kuleaşan, H., 2014. Fourier Dönüşümlü Kızılötesi (FTIR) Spektroskopisi ve g1da analizlerinde kullanımı. GIDA 39 (4): 235241.

Cassagne, C., Normand, A.C., L'ollivier, C., Ranque, S., Piarroux, R. (2016). Performance of MALDI-TOF MS platforms for fungal identification. Mycoses 59(11): 678-690.

Cassagne, C., Ranque, S., Normand, A.C., Fourquet, P., Thiebault, S., Planard, C., Hendrickx, M., Piarroux, R. (2011). Mould routine identification in the clinical laboratory by matrix-assisted laser desorption ionization timeof-flight mass spectrometry. PLoS One 6(12): e28425.

Chalupová, J., Raus, M., Sedlářová, M., Šebela, M. (2014). Identification of fungal microorganisms by MALDI-TOF mass spectrometry. Biotechnol Adv 32(1): 230-241.

Ciardo, D.E., Schär, G., Altwegg, M., Böttger, E.C., Bosshard, P.P. (2007). Identification of moulds in the diagnostic laboratory-an algorithm implementing molecular and phenotypic methods. Diagn Microbiol Infect Dis 59(1): 49-60.

Criseo, G., Scordino, F., Romeo, O. (2015). Current methods for identifying clinically 
important cryptic Candida species. J Microbiol Methods 111: 50-56.

Çavuş, S., Tornuk, F., Sarioglu, K., Yetim, H. (2018). Determination of mold contamination and aflatoxin levels of the meat products/ingredients collected from Turkey market.J Food Safety 38(5): e12494, doi: $10.1111 /$ jfs.12494.

Decontardi, S., Soares, C., Lima, N., Battilani, P. (2018). Polyphasic identification of Penicillia and Aspergilli isolated from Italian grana cheese. Food Microbiol 73:137-149. https://doi.org/10.1016/j.fm.2018.01.012

Drissner, D., Freimoser, F.M. (2017). MALDITOF mass spectroscopy of yeasts and filamentous fungi for research and diagnostics in the agricultural value chain. Chem Biol Technol Agric 4(1): 13, doi: 10.1186/s40538-017-0095-7.

Dulla, E.L., Kathera, C., Gurijala, H.K., Mallakuntla, T.R., Srinivasan, P., Prasad, V., Mopati R.D., Jasti, P.K. (2016). Highlights of DNA Barcoding in identification of salient microorganisms like fungi. J Mycol Med 26(4): 291297.

El-Fadaly, H.M., El-Kadi, S.M., Hamad, M.N., Habib, A.A. (2015). Isolation and identification of Egyptian Ras Cheese (Romy) contaminating fungi during ripening period. J Microbiol Res 5(1): 1-10.

Erukhimovitch, V., Tsror, L., Hazanovsky, M., Talyshinsky, M., Mukmanov, I., Souprun, Y., Huleihel, M. (2005). Identification of fungal phyto-pathogens by Fourier-Transform Infrared (FTIR) microscopy. J Agric Technol 1(1): 145-152.

Fatimoh, A.O., Moses, A.A., Adekunle, O.B., Dare, O.E. (2017). Isolation and identification of rot fungi on post-harvest of pepper (Capsicum annuum L.) fruits. AASCIT J Biol 3(5): 24-29.

Fapohunda, S.O., Moore, G.G., Aroyeun, S.O., Ayeni, K.I., Aduroja, D.E., Odetunde, S.K. (2018). Isolation and characterization of fungi isolated from Nigerian cocoa samples. Current Life Sciences 4(3): 46-52.

Fischer, G., Braun, S., Thissen, R., Dott, W. (2006). FT-IR spectroscopy as a tool for rapid identification and intra-species characterization of airborne filamentous fungi.J Microbiol Methods 64(1): 63-77.

Flórez, A.B., Álvarez-Martín, P., López-Díaz, T.M., Mayo, B. (2007). Morphotypic and molecular identification of filamentous fungi from Spanish blue-veined Cabrales cheese, and typing of Penicillium roqueforti and Geotrichum candidum isolates. Int Dairy J 17(4): 350-357.

Francesca, N., Gaglio, R., Stucchi, C., De Martino, S., Moschetti, G., Settanni, L. (2018). Yeasts and moulds contaminants of food ice cubes and their survival in different drinks. $J A p p l$ Microbiol 124(1): 188-196.

Galagan, J.E., Calvo, S.E., Borkovich, K.A., Selker, E.U., Read, N.D., Jaffe, D., et al., (2003). The genome sequence of the filamentous fungus Neurospora crassa, Nature, 422: 859-868.

Garcia, M.V., Parussolo, G., Moro, C.B., Bernardi, A.O., Copetti, M.V. (2018). Fungi in spices and mycotoxigenic potential of some Aspergilli isolated. Food Microbiol 73: 93-98.

Garnier, L., Valence, F., Pawtowski, A., Auhustsinava-Galerne, L., Frotté, N., Baroncelli, R., Deniel, F., Coton, E., Mounier, J. (2017). Diversity of spoilage fungi associated with various French dairy products. Int J Food Microbiol 241: 191-197.

Gautier, M., Ranque, S., Normand, A.C., Becker, P., Packeu, A., Cassagne, C., L'Ollivier, C., Hendrickx, M., Piarroux, R. (2014). Matrixassisted laser desorption ionization time-of-flight mass spectrometry: revolutionizing clinical laboratory diagnosis of mould infections. Clin Microbiol Infect 20(12): 1366-1371.

Hawksworth, D.L. (2015). Naming fungi involved in spoilage of food, drink, and water. Curr Opin Food Sci 5: 23-28.

Hayaloğlu, A.A., Kırbağ, S. (2007). Microbial quality and presence of moulds in Kuflu cheese. Int J Food Microbiol 115(3): 376-380.

Hendrickx, M. (2017). MALDI-TOF MS and filamentous fungal identification: A Success Story. Curr Fungal Infect Rep 11(2): 60-65. 
Heperkan, D. (2014). Mikotoksinlerin Önemi. Gidalarda Mikotoksinler, Heperkan, D. (ed.), Sidas Medya Ltd. Şti., İzmir, Türkiye, s. 1-22.

Hertwig, A.M., Sant'Ana, A.S., Sartori, D., da Silva, J.J., Nascimento, M.S., Iamanaka, B.T., Fungaro, M.H.P., Taniwaki, M.H. (2018). Realtime PCR-based method for rapid detection of Aspergillus niger and Aspergillus welwitschiae isolated from coffee. J Microbiol Methods 148: 87-92, doi: 10.1016/j.mimet.2018.03.010.

Houbraken, J., Samson, R.A. (2017). Current taxonomy and identification of foodborne fungi. Curr Opin Food Sci 17: 84-88.

Jedidi, I., Soldevilla, C., Lahouar, A., Marín, P., González-Jaén, M.T., Said, S. (2018). Mycoflora isolation and molecular characterization of Aspergillus and Fusarium species in Tunisian cereals. Saudi J Biol Sci 25(5): 868-874.

Jiang, J., Qiao, X., He, R. (2016). Use of NearInfrared hyperspectral images to identify moldy peanuts. J Food Eng 169: 284-290.

Jogee, P.S., Ingle, A.P., Rai, M. (2017). Isolation and identification of toxigenic fungi from infected peanuts and efficacy of silver nanoparticles against them. Food Control 71: 143-151.

Kandpal, L.M., Cho, B. (2014). A Review of the Applications of Spectroscopy for the Detection of Microbial Contaminations and Defects in Agro Foods. J Biosyst Eng 39(3):215-226.

Kim, Y., Nandakumar, M.P., Marten, M.R. (2007). Proteomics of filamentous fungi. Trends Biotechnol 25(9): 395-400.

Koffi, Y.F., Diguta, C., Alloue-Boraud, M., Koffi, L.B., Dje, M, Gherghina, E, Matei, F. (2019). PCR-ITS-RFLP identification of pineapple spoilage fungi. Rom Biotechnol Lett 24:418-424.

Kure, C.F., Skaar, I., Brendehaug, J. (2004). Mould contamination in production of semi-hard cheese. Int J Food Microbiol 93(1): 41-49.

Lecellier, A., Gaydou, V., Mounier, J., Hermet, A., Castrec, L., Barbier, G., Ablain, W., Manfait, M., Toubas, D., Sockalingum, G.D. (2015). Implementation of an FTIR spectral library of 486 filamentous fungi strains for rapid identification of molds. Food Microbiol 45: 126134.

Lecellier, A., Mounier, J., Gaydou, V., Castrec, L., Barbier, G., Ablain, W., Manfait M., Toubas, D., Sockalingum, G.D. (2014). Differentiation and identification of filamentous fungi by highthroughput FTIR spectroscopic analysis of mycelia. Int J Food Microbiol 168: 32-41.

Lima, N., Santos, C. (2017). MALDI-TOF MS for identification of food spoilage filamentous fungi. Curr Opin Food Sci 13: 26-30.

Lozano-Ojalvo, D., Rodríguez, A., Cordero, M., Bernáldez, V., Reyes-Prieto, M., Córdoba, J.J. (2015). Characterisation and detection of spoilage mould responsible for black spot in dry-cured fermented sausages. Meat Sci 100: 283-290.

Luethy, P.M., Zelazny, A.M. (2018). Rapid onestep extraction method for the identification of molds using MALDI-TOF MS. Diagn Microbiol Infect Dis 91(2): 130-135.

Lüthje, P., Pranada, A.B., Carruthers-Lay, D., Desjardins, M., Gaillot, O., Wareham, D., Ciesielczuk, H., Özenci, V. (2017). Identification of microorganisms grown on chromogenic media by MALDI-TOF MS. J Microbiol Methods 136: 1720.

Mailafia, S., Okoh, G.R., Olabode, H.O.K., Osanupin, R. (2017). Isolation and identification of fungi associated with spoilt fruits vended in Gwagwalada market, Abuja, Nigeria. Vet World 10(4):

393-397, doi: 10.14202/vetworld.2017.393-397

Miguel, M.G.D.C.P., de Castro Reis, L.V., Efraim, P., Santos, C., Lima, N., Schwan, R.F. (2017). Cocoa fermentation: Microbial identification by MALDI-TOF MS and sensory evaluation of produced chocolate. LWT-Food Sci Technol 77: 362-369, doi: 10.1016/j.lwt.2016.11.076.

Moubasher, A.A., Abdel-Sater, M.A., Soliman, Z.S.M. (2018). Yeasts and filamentous fungi associated with some dairy products in Egypt. $J$ Mycol Med 28(1): 76-86.

Oberle, J., Dighton, J., Arbuckle-Keil, G. (2015). Comparison of methodologies for separation of fungal isolates using Fourier Transform Infrared 
(FTIR) spectroscopy and Fourier Transform Infrared-Attenuated total reflectance (FTIRATR) microspectroscopy. Fungal Biol 119(11): 1100-1114.

Oliveira, M.M.E., Santos, C., Sampaio, P., Romeo, O., Almeida-Paes, R., Pais, C., Lima, N., Zancopé-Oliveira, R.M. (2015). Development and optimization of a new MALDI-TOF protocol for identification of the Sporotbrix species complex. Res Microbiol 166(2): 102-110.

Panda, A., Ghosh, A.K., Mirdha, B.R., Xess, I., Paul, S., Samantaray, J.C., Srinivasan A., Khalil, S., Rastogi, N., Dabas, Y. (2015). MALDI-TOF mass spectrometry for rapid identification of clinical fungal isolates based on ribosomal protein biomarkers. J Microbiol Methods 109: 93-105.

Panelli, S., Buffoni, J. N., Bonacina, C., Feligini, M. (2012). Identification of moulds from the Taleggio cheese environment by the use of DNA barcodes. Food Control 28(2): 385-391.

Pinheiro, A. C., Macedo, M. F., Jurado, V., SaizJimenez, C., Viegas, C., Brandão, J., Rosado, L. (2011). Mould and yeast identification in archival settings: Preliminary results on the use of traditional methods and molecular biology options in Portuguese archives. Int Biodeter Biodegr 65(4): 619-627.

Pitt, J.I., Hocking, A.D. (2009). Fungi and Food Spoilage. 3rd Edition, Springer, New York, 519p, ISBN: 978-0-387-92206-5.

Quéro, L., Girard, V., Pawtowski, A., Tréguer, S., Weill, A., Arend, S., Cellière, B., Polsinelli, S., Monnin, V., Belkum, A.V., Nodet, P., Mounier, J., Vasseur, V. (2018). Development and application of MALDI-TOF MS for identification of food spoilage fungi. Food Microbiol 1-13, doi: 10.1016/j.fm.2018.05.001.

Raja, H.A., Miller, A.N., Pearce, C.J., Oberlies, N.H. (2017). Fungal identification using molecular tools: a primer for the natural products research community. J Nat Prod 80(3): 756-770.

Ranque, S., Normand, A.C., Cassagne, C., Murat, J.B., Bourgeois, N., Dalle, F., Gari-Toussaint, M., Fourquet, P., Hendrickx, M., Piarroux, R. (2014). MALDI-TOF mass spectrometry identification of filamentous fungi in the clinical laboratory. Mycoses 57(3): 135-140.

Rico-Munoz, E., Samson, R.A., Houbraken, J. (2018). Mould spoilage of foods and beverages: Using the right methodology. Food Microbiol 1-12, doi: 10.1016/j.fm.2018.03.016.

Ruiz-Moyano, S., Benito, M.J., Martín, A., Aranda, E., Hernández, A., Córdoba, M.G. (2009). Characterization of molds isolated from smoked paprika by PCR-RFLP and micellar electrokinetic capillary electrophoresis. Food Microbiol 26:776-782.

Sacristán, N., Mayo, B., Fernández, E., Fresno, J.M., Tornadijo, M.E., Castro, J.M. (2013). Molecular study of Geotrichum strains isolated from Armada cheese. Food Microbiol 36(2): 481487.

Samson, R. A. (2010). Food and indoor fungi. CBSKNAW Fungal Biodiversity Centre, ISBN: 9789070351823.

Sanguinetti, M., Posteraro, B. (2017). Identification of molds by matrix-assisted laser desorption ionization-time of flight mass spectrometry. J Clin Microbiol 55(2): 369-379.

Santos, C., Fraga, M.E., Kozakiewicz, Z., Lima, N. (2010). Fourier transform infrared as a powerful technique for the identification and characterization of filamentous fungi and yeasts. Res Microbiol 161(2): 168-175.

Shapaval, V., Moretro, T., Suso, H.P., Åsli, A.W., Schmitt, J., Lillehaug, D., Martens, H., Böcker, U., Kohler, A. (2010). A high-throughput microcultivation protocol for FTIR spectroscopic characterization and identification of fungi. $J$ Biophotonics 3(8-9): 512-521.

Shapaval, V., Møretrø, T., Wold Åsli, A., Suso, H.P., Schmitt, J., Lillehaug, D., Kohler, A. (2017). A novel library-independent approach based on high-throughput cultivation in Bioscreen and fingerprinting by FTIR spectroscopy for microbial source tracking in food industry. Lett Appl Microbiol 64(5): 335-342.

Shehu, K., Tafinta, I.Y. (2017). Identification of fungi associated with fruit rot of coconut 
(Cocosnucifera L.) in Sokoto State, North-Western Nigeria. J Zool Biosi Res 1(1): 20-23.

Sivaraman, G.K., Visnuvinayagam, S., Jha, A.K., Remya, S., Renuka, V., Ajeesh, K., Vanik, D. (2018). Molecular divergence and identification of Aspergillus species in dry fishes of Gujarat India. Proceedings of the National Academy of Sciences, India Section B: Biological Sciences 88(2): 505-515.

Srivastava, S., Gupta, P.S., Lal, S., Sinha, O.K. (2017). Rapid identification of endophytic fungi of sugarcan (Saccharum spp. hybrid) using PCRRFLP of rDNA. J Environ Biol 38(1):21-26.

Stübiger, G., Wuczkowski, M., Mancera, L., Lopandic, K., Sterflinger, K., Belgacem, O. (2016). Characterization of yeasts and filamentous fungi using MALDI lipid phenotyping. J Microbiol Methods 130: 27-37.

Surženko, M., Kontram, K., Sarand, I. (2017). PCR-based fingerprinting and identification of contaminative fungi isolated from rye breads. Agron Res 15(1): 288-297.

Trabelsi, H., Neji, S., Hadrich, I., Khemakhem, N., Sellami, H., Makni, F., Ayadi, A. (2019). Contribution of the internal transcribed spacer regions to the detection and identification of human fungal pathogens. Curr Res Transl Med 67(3):100-106.

Ushasri, K., Kumar, B.A. (2018). Isolation and identification of fungal pathogen from (Allium Cepa L.) In Piler vegetable market, Andhrapradesh, India. WJPPS 7(3): 955-963.
Vij, D.R., (2007). Handbook of applied solid state spectroscopy. Springer Science and Business Media, New York, 742p, ISBN: 0-387-32497-6.

Villalobos, M.C., Serradilla, M.J., Martín, A., Hernández-León, A., Ruíz-Moyano, S., Córdoba, M.G. (2017). Characterization of microbial population of breba and main crops (Ficus carica) during cold storage: Influence of passive modified atmospheres (MAP) and antimicrobial extract application. Food Microbiol 63:35-46. https://doi.org/10.1016/j.fm.2016.10.035

Wakai, S., Arazoe, T., Ogino, C., Kondo, A. (2017). Future insights in fungal metabolic engineering. Bioresour Technol 245: 1314-1326.

Wattal, C., Oberoi, J.K., Goel, N., Raveendran, R., Khanna, S. (2017). Matrix-assisted laser desorption ionization time of flight mass spectrometry (MALDI-TOF MS) for rapid identification of microorganisms in the routine clinical microbiology laboratory. Eur J Clin Microbiol Infect Dis 36(5): 807-812.

Zhao, J., Liu, W., Liu, D., Lu, C., Zhang, D., Wu, H., Dong, D., Meng, L. (2018). Identification and evaluation of Aspergillus tubingensis as a potential biocontrol agent against grey mould on tomato. $J$ Gen Plant Pathol 84: 148-159. 